\title{
FROM IMPACTFUL RESEARCH TO SUSTAINABLE INNOVATIONS FOR SUBSISTENCE MARKETPLACES
}

\author{
Cheryl Nakata, University of Illinois, Chicago \\ Madhubalan Viswanathan, University of Illinois, Urbana-Champaign
}

October 2011

Send correspondence to Cheryl Nakata, Department of Managerial Studies, College of Business Administration, University of Illinois at Chicago, 601 S. Morgan (MC 243), Chicago, IL 60607, cnakat1@ uic.edu, 312-355-1337 (ph), 312-996-3559 (fx). Madhubalan Viswanathan, Department of Business Administration, College of Business, University of Illinois at UrbanaChampaign, 61 Wohlers Hall, 1206 South Sixth Street, Champaign IL, 60820, mviswana@illinois.edu, 217-333-4550 (ph)., 217-244-7969 (fx). 


\begin{abstract}
This special issue on sustainable innovation for subsistence marketplaces results from the Third Subsistence Marketplaces Conference organized by the University of Illinois, UrbanaChampaign and the University of Illinois, Chicago in July 2010. The conference brought together researchers, managers, government officials, and nonprofit directors for lively exchanges on how to better serve, understand, and innovate in sustainable ways for bottom of the pyramid markets. Some of the papers from that conference are presented here, building on prior conferences and adding to a growing body of knowledge about these dynamic and complex markets. Topics range from entrepreneurship and strategic alliances to consumer literacy and new product development. As this special issue brings new insights on subsistence marketplaces, the hope is that all who live in these geographies will see the promise of economic inclusiveness and quality of life realized.
\end{abstract}

Keywords: Subsistence marketplaces, Bottom of the Pyramid, Sustainable innovations. 


\section{From Impactful Research to Sustainable}

\section{Innovations for Subsistence Marketplaces}

The University of Illinois at Urbana-Champaign and University of Illinois at Chicago, with the participation of Dominican University and DePaul University, organized and held the Third Subsistence Marketplace Conference on July 9-11, 2010 in Chicago at the University of Illinois at Chicago campus. As with the first conference in August 2006 and the second in June 2008, the aim of this gathering was better understanding and responding to consumers and entrepreneurs who live at or near subsistence. "Subsistence," a descriptive not evaluative term, connotes being resource-poor, or barely having sufficient resources for day-to-day living, yet being possibly rich in other ways, such as social relations and networks (Viswanathan and Rosa, 2007; 2009). The conference specifically recognized "subsistence marketplaces," which pre-exist in their own right - not just as markets to sell to but as individuals, communities, consumers, entrepreneurs, and businesses to buy and learn from (Viswanathan and Sridharan, 2009). These marketplaces are largely concentrated in developing countries and regions such as Brazil, India, and SubSaharan Africa.

The conference uniquely centered on commercial and social innovations for subsistence marketplaces that are ecologically, economically, and socially sustainable. As businesses, governments, and nonprofit organizations seek to know and serve these communities, innovation and sustainability have become pathways to do so. Traditional forms of aid and economic development have met with limited success in ameliorating poverty and improving the quality of life for many. To explore the pathways of innovation and sustainability, the program included plenary panels, participatory workshops, keynote speeches by thought leaders, special sessions 
and research papers. The conference was inter-disciplinary and a range of perspectives was offered, from the fields of design and marketing to computer science and social work. It was likewise cross-sectoral, bringing together academicians, social enterprise leaders, business practitioners, and government officials. The interdisciplinary and cross-sectoral representation enriched and invigorated the exchange of ideas. The perspective maintained throughout was bottom up, or beginning with a micro-level understanding of subsistence consumers, entrepreneurs, and marketplaces to derive macro-level implications for organizational strategies and public policy. The bottom up view was taken to develop sustainable business models and technological innovations that positively impact subsistence marketplaces, and in fact, all marketplaces.

The program began with sessions on subsistence consumption and entrepreneurship. Concurrent sessions focused on co-creating impactful innovations and innovative partnerships in subsistence settings. Later that day, keynote speaker Pradeep Kashyap provided inspiring insights about his pioneering and inclusive marketing practices in rural India, where he created a cutting-edge organization with a social conscience called MART. Panels in the afternoon addressed topics such as creating impact through business and social innovations, including a session on design principles for social projects by IDEO, one of the world's foremost design consultancies. Each panel brought together practitioners with extraordinary experience working in subsistence marketplaces around the world. The second day featured concurrent research sessions spanning consumer behavior to subsistence entrepreneurs and business strategy to financial and technological innovations. We also came together to remember C.K. Prahalad, the McCracken Distinguished University Professor of Corporate Strategy at the University of Michigan. The conference and this special section issue is dedicated 
to him. What better way to articulate the importance of the theme of innovation and sustainability than to recall the life of the individual who in many ways brought the Bottom of the Pyramid to the attention of businesses worldwide, highlighting how the creative ideas and energies of people can bring about new and powerful solutions to communities and places easily dismissed as economically hopeless. While C.K. Prahalad's work epitomized innovation and impact in so many areas - perhaps none was greater than his pathbreaking ideas on the Bottom of the Pyramid. A life of innovation and impact indeed! Sharing memories about him were current and former colleagues and friends (Ted London of the University of Michigan and Tom Murtha of the University of Illinois at Chicago, Dean Stefanie Lenway of Michigan State University, and Madhu Viswanathan of the University of Illinois at Urbana-Champaign). In the same spirit, we also recognize in this special section issue the amazing contribution of another individual. Robin Orr was an extension specialist at the University of Illinois at UrbanaChampaign. Her work on nutrition education touched the lives of a million people in the state of Illinois, expanding to every county during her tenure. Robin Orr and C. K. Prahalad are reminders that true measures of innovation and impact extend well beyond immediate circles - to lives changed for the better and opportunities created for those without. The formal program concluded with a session on bringing subsistence marketplaces into the management curriculum and closing remarks. It was exciting to hear first-hand testimonies from students who took courses to carry out innovation projects in India with subsistence communities - students whose own lives were positively transformed by the experience.

We have many people to thank for making this conference possible. We begin with gratitude to Dean Larry DeBrock (University of Illinois at Urbana-Champaign), Dean Stefanie 
Lenway (Michigan State University), and Dean Michael Pagano (University of Illinois at Chicago). We also thank Al Page (University of Illinois at Chicago), Sharon Shavitt (University of Illinois at Urbana-Champaign), and Steve Sonka (University of Illinois at Urbana-Champaign) for their invaluable support. We thank Kathy Dhanda of DePaul University and Al Rosenbloom of Dominican University for their involvement as track chairs and sponsors for this conference. Emilie Wagner and Janette Salamanca of the University of Illinois at Chicago worked tirelessly to make the conference a success as event coordinators. Our mementos were made by a subsistence entrepreneur in Colombia and we thank Jose Rosa from the University of Wyoming for his efforts to make this possible. We acknowledge with appreciation the Stellner Fund, and the Center for International Business Education and Research, College of Business, and the Office of Public Engagement, all at the University of Illinois at Urbana-Champaign, along with the College of Business Administration and the Department of Managerial Studies at the University of Illinois at Chicago for their financial support.

Our hope is that the conference improves the teaching, research, and practice tied to subsistence marketplaces and ultimately empowers individuals who comprise these communities. The interconnections between livelihoods and the environment that we learned through this conference are stark and constant realities in subsistence marketplaces, but they are also avenues for innovation and sustainable solutions. It was very fitting that we had so many students and young scholars and practitioners in our midst as the challenge of enabling subsistence marketplaces to be sustainable marketplaces—one the most important in the $21^{\text {st }}$ century—will only be addressed by those with fresh ideas and insights as well as helpful tools and passion.

\section{CONTENTS OF THE SPECIAL SECTION}


This conference, titled "From Impactful Research to Sustainable Innovation," built on the momentum from the first two conferences held in 2006 and 2008. Product and Market Development for Subsistence Marketplaces: Consumption and Entrepreneurship Beyond Literacy and Resource Barriers, and Sustainable Consumption and Commerce For a Better World were the themes of those earlier conferences, respectively. The resulting articles were published as an edited volume (Rosa and Viswanathan, 2007) and a special issue of the Journal of Business Research (Viswanathan, Rosa, and Cherian, 2010).

Continuing this tradition, this special section of the Journal of Business Research represents another step forward in our understanding of subsistence marketplaces. It hopefully is a small contribution toward generating relevant insights from research, which in turn translates into sustainable innovations for these peoples and geographies. We begin by highlighting the articles.

At a micro or individual level, in keeping with the reality that entrepreneurship is one of the few means of income generation in subsistence marketplaces, several articles here investigate issues tied with entrepreneurial activities. Toledo-López, Díaz-Pichardo, Jiménez-Castañeda, and Sánchez-Medina present work on how entrepreneurs in subsistence marketplaces define and achieve success. Focusing on subsistence entrepreneurs in the artisanal industry in Oaxaca, Mexico, the authors create a typology of entrepreneurs based on qualitative and quantitative data. DeBerry-Spence and Elliot study everyday challenges to microentrepreneurship in Ghana, West Africa, focusing on problems affecting daily business operations. They use a qualitative study of arts and crafts microentrepreneurs to highlight these challenges and long-term barriers and how entrepreneurs overcome them.

At a micro or individual level from the consumer side, two articles provide new insights on lower literate consumers, who are prevalent in subsistence marketplaces. Jae and Viswanathan 
investigate conditions under which the information processing of lower literate consumers is diminished or elevated with respect to product warning statements. They find that congruent pictures without text benefit lower literate consumers, leveraging strengths in pictoral processing and minimizing weaknesses in comprehension and memory. Gau, Jae, and Viswanathan examine ways of studying low literate, low-income individuals in both advanced and emerging economies. The authors review methods, including qualitative approaches such as participant observation, but give special attention to experiments. Furthermore, the scholars explore issues in applying these designs, as well as concomitant administrative difficulties.

At the meso-level of analysis, Waeyenburg and Hens examine international expansion of multinationals from developed countries to BoP markets. Focusing on product innovations, the authors use a case study on Philips Lighting, to discuss how factors such as institutional distance limit transferability and development of capabilities during international expansion.

Moving to a macro level of analysis, several papers examine alliances in subsistence marketplaces. Murphy, Perrot, and Rivera study the use of cross-sectoral alliances between the for-profit and nonprofit sectors. The authors evaluate the utility of absorptive capacity theory and propose and argue for a new concept called relational capacity for social innovation as more suitable for subsistence marketplaces. A related paper by Sakarya, Bodur, Yildirim-Oktem, and Selekler-Goksen on social alliances for social transformation takes a systems approach to understand why and with what consequences parties establish such alliances. Based on case studies of six social alliances in Turkey, patterns are observed that indicate social alliances can be instrumental in social change, bringing about innovative and multiple transformations. RiverSantos, Rufin, and Kolk investigate the impact of institutions on partnerships in subsistence markets. Using rationale based on institutional theory and transaction cost economics, they 
discuss such issues as how partnerships adapt to institutions specific to subsistence markets and external institutions and whether partnerships include multiple partners from multiple sectors.

A number of articles at the level of sustainable development focus on the intersection of community and business. Corus and Ozanne propose a deliberative democratic approach to stakeholder engagement in subsistence markets. They evaluate four methods and applications for improving participation and deliberation that can enable marginalized communities to affect corporate actions relating to their well-being. Mandiberg studies low-income users of social services in the United States. Viewing social-service user populations as identity communities, the article describes a methodology for designing business development projects that represents a market-based approach to meeting needs. Elaydi introduces Terroir Strategy, a community level perspective on a firm's ability to build capabilities around community resources. A Business-for-Community Framework is presented for creating a firm that captures the community's core values and whose success is intertwined with community wellbeing.

We add an important and heartfelt thank you to the reviewers who lent their expertise to make this special issue possible: Stacey Baker (University of Wyoming), Frank Boons (Erasmus University, Rotterdam), Dana Brown (Oxford University), George Curry (Curtin University), Benet DeBerry-Spence (University of Illinois, Chicago), Kathy Dhanda (DePaul University), Raed Elaydi (Roosevelt University), Esi Abbam Elliot (University of Illinois, Chicago), Roland Gau (University of Texas, El Paso), Paul C. Godfrey (Brigham Young University), James Harris (St. Norbert College) Ron Paul Hill (Villanova University), James Mandiberg (Columbia University), Kevin Mckague (York University), Phyllis Mansfield (Penn State Erie), Susan Mudambi (Temple University), Julie Ozanne (Virginia Tech University, Blacksburg), Robin Ritchie (Carleton University, Ottawa, Canada), Jose Antonio Rosa (University of Wyoming), Al 
Rosenbloom (Dominican University), Robin Ritchie (Carleton University), Miguel RiveraSantos ( Babson College), Carlos Rufin (Suffolk University), Sema Sakarya (Bogazici University), Christian Seelos (Center on Philanthropy and Civil Society, Stanford University), Srinivas Sridharan (Monash University, Melbourne, Australia), Arcelia Toledo-Lopez (CIIDIR, Instituto Politécnico Nacional, Unidad Oaxaca), Sofie Van den waeyenberg (Vrije Universiteit Brussel), Srinivas Venugopal (University of Illinois, Urbana-Champaign), Kelly Weidner (University of Illinois, Chicago), and Justin Webb (Oklahoma State University) for their invaluable efforts in reviewing articles submitted for this special issue.

The hope is that this special issue will spur others to not only research the increasingly vital intersection of sustainable innovation and subsistence marketplaces, but also implement cocreated solutions that respect the dignity, resources, and self-determination of those who have much to show and teach the rest of the world. 


\section{References}

Viswanathan, M. \& Rosa, J. (2007). Product and market development for subsistence marketplaces: consumption and entrepreneurship beyond literacy and resource barriers. In

Product and Market Development for Subsistence Marketplaces: Consumption and

Entrepreneurship Beyond Literacy and Resource Barriers. Editors, Jose Rosa and Madhu

Viswanathan, Advances in International Management Series, Joseph Cheng and Michael Hitt, Series Editors, 1-17, Elsevier.

Viswanathan, M. \& Rosa J. (2010). Understanding subsistence marketplaces: Toward sustainable consumption and commerce for a better world. Journal of Business Research, 63(6), 535-537.

Viswanathan M., \& Sridharan S. (2009). From subsistence marketplaces to sustainable marketplaces: A bottom-up perspective on the role of business in poverty alleviation. Ivey Business Journal, March/April. 